\title{
Variants of Escherichia coli giving the appearance of mixed growths in urine
}

\author{
G. L. NICHOLS ${ }^{1}$
}

From the Department of Microbiology, Northwick Park Hospital, Harrow

SYNOPSIS Urines from patients with symptoms of urinary tract infection yielded mixed growths of different colony types of Escherichia coli. The different colony types were found to be variants of single infecting strains caused by mutation or by phage action. It is suggested that care should be exercised in the interpretation of apparently mixed growths from urine.

A mixed growth from a mid-stream specimen of urine is generally considered to indicate contamination during collection of the urine or, very rarely, a mixed infection. This paper describes three cases in which strict application of this generalization might have led to a misleading report.

\section{Case 1}

A specimen of mid-stream urine from a woman with frequency of micturition, dysuria, and back pain was examined routinely for cells and culture. The cell count in a modified Fuchs Rosenthal chamber showed leucocytes $>1000$ per $\mu$ l and red blood cells $<1$ per $\mu$ l. The urine was cultured by a standard $(3 \mathrm{~mm})$ wire-loop method on Oxoid Cystein Lactose Electrolyte Deficient Agar (CLED).

After incubation at $37^{\circ} \mathrm{C}$ for 18 hours there was an apparently mixed growth of three organisms, each producing a different type of colony and presenting between 10000 and 100000 , with a total of more than 100000 organisms per $\mathrm{ml}$ of urine (fig 1, which is not, however, the original plate). The three colony types were all $2 \mathrm{~mm}$ in diameter, circular, convex, and entire. One was an irregular surfaced bright lactose fermenter; the second was an irregular surfaced non-lactose fermenter which on re-incubation for $\mathbf{4 8}$ hours was weakly lactose-fermenting; the third was a smooth-surfaced lactose fermenter. All three organisms retained their distinctive colony types when subcultured on CLED, MacConkey's, and blood agar. When kept at room temperature for two weeks a fine surface growth appeared around all

${ }^{1}$ Present address: Department of Microbiology, Worthing Hospital, Worthing, Sussex

Received for publication 4 March 1975.

three colony types, and on subculture this growth $N$ yielded identical colony forms with the exception of $N$ the smooth lactose fermenter which yielded a pure 0 growth of bright lactose-fermenting colonies.

All three organisms gave identical biochemical

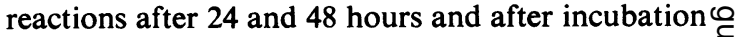
for five days at $37^{\circ} \mathrm{C}$. They also gave similar in- $\Phi$

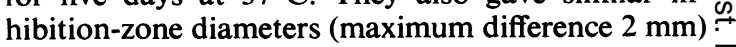
to a range of antibacterial drugs; when compared $\frac{T}{0}$ with a sensitive control (E. coli NCTC no. 10418), $\stackrel{\circ}{\stackrel{\circ}{\circ}}$ they were sensitive to ampicillin, sulphafurazole, $\frac{?}{\mathbb{Q}}$ 
co-trimoxazole, trimethoprim, nitrofurantoin, cephalexin, carbenicillin, gentamicin, polymyxin, naladixic acid, kanamycin, neomycin, streptomycin, and chloramphenicol, and resistant to tetracycline.

The three organisms were serotyped and all were found to be $E$. coli 0101 . The smooth lactose fermenter, but not the other two strains, also possessed the $\mathrm{K} 30$ (A) capsular antigen. Phage could not be demonstrated after filtration of broth cultures of the three organisms. It is thought that the parent strain was the one that possessed the K30 (A) antigen.

$E$. coli 0101 is not one of the most common $O$ serotypes found in urinary tract infections (Spencer et al, 1968; O'Grady et al, 1970; Mabeck et al, 1971; Dootson et al, 1973) although it has been isolated from this source (Grüneberg et al, 1968). From consideration of the clinical history and laboratory tests it is suggested that the patient was suffering from a urinary tract infection caused by $E$. coli 0101 .

\section{Case 2}

A mid-stream specimen of urine from a male patient with dysuria, pyrexia, and loin pain showed a cell count of leucocytes $>1000$ and red blood cells $<1$ per $\mu$ l.

After incubation at $37^{\circ} \mathrm{C}$ for 18 hours there was an apparently mixed growth of three organisms, each representing more than 100000 organisms per $\mathrm{ml}$ of urine. One colony type was $0.5 \mathrm{~mm}$ irregular surfaced, bright lactose fermenter; the second was $0.5 \mathrm{~mm}$ irregular surfaced, pale lactose fermenter; the third was a minute colony. Only the pale lactose fermenter grew pure on subculture; the other two colony types produced growths similar to that of the original plate.

Single isolated colonies of the three colony types were grown in broth and were used for biochemical tests. All three types gave identical biochemical reactions. They also gave similar inhibition-zone diameters to a range of antibacterial drugs; when compared with a sensitive control they were sensitive to ampicillin, sulphafurazole, co-trimoxazole, tetracycline, nitrofurantoin, cephalexin, carbenicillin, gentamicin, polymixin, naladixic acid, kanamycin, and streptomycin.

CLED agar plates were flooded with broth culture of the three colony types; the broths were then filtered, checked for sterility, and titrated on the three inoculated plates for the presence of phage (fig 2). Filtrate from the pale lactose fermenter did not contain phage whereas the other two did. There was deepening of the yellow indicator around the plaques. The bacteria-free filtrate from the bright lactose fermenter was then added to broth containing

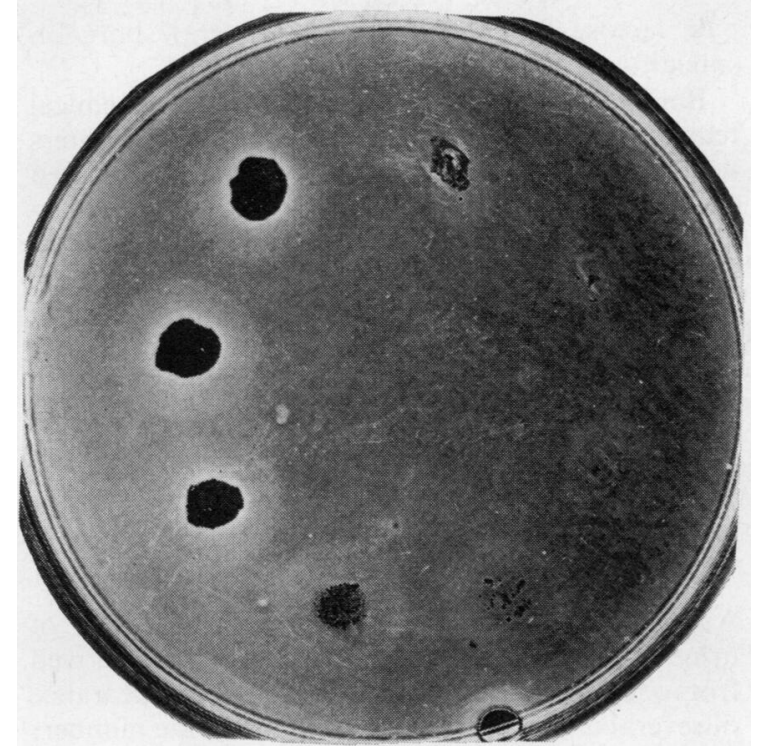

Fig 2 Phage titration against the Escherichia coli from case 2 on CLED agar, showing brighter growth around plaques

the pale lactose fermenter, and this was then inoculated onto a fresh CLED plate. After 18 hours' incubation at $37^{\circ} \mathrm{C}$ the three colony types were present.

From these results it was concluded that only one bacterial strain was present and that this was acted on by a phage to give colonial variants. The increased brightness of the affected colonies may be due to phage lysing the bacterial cell wall, releasing the galactosidase normally held inside. The organism was serotyped and was found to be E. coli 02 , which is common in urinary tract infections (Grüneberg et al, 1968; Spencer et al, 1968; O'Grady et al, 1970; Mabeck et al, 1971; Dootson et al, 1973). From consideration of the clinical history and laboratory tests it is suggested that the patient was suffering from a urinary tract infection caused by E. coli 02 .

\section{Case 3}

A mid-stream specimen of urine from a female patient with peripheral vascular disease, uraemia, and anaemia showed a cell count of leucocytes 110 and red blood cells $<1$ per $\mathrm{ml}$. After incubation at $37^{\circ} \mathrm{C}$ for 18 hours there was an apparently mixed growth of two organisms, each representing $>100000$ organisms per $\mathrm{ml}$ of urine. One colony was $1 \mathrm{~mm}$ irregular surfaced, bright lactose fermenter and the other $1.5 \mathrm{~mm}$ irregular surfaced, 
pale lactose fermenter. Both types grew pure on subculture.

Both colony types gave identical biochemical reactions and similar zone inhibition diameters to a range of antibacterial drugs; when compared with a sensitive control they were sensitive to ampicillin, sulphonamide, co-trimoxazole, tetracycline, nitrofurantoin, and cephalexin.

Both colonies were serotyped and found to be $E$. coli 075 , which is common in urinary tract infections. From consideration of the clinical history and laboratory tests it is suggested that the patient was suffering from a urinary tract infection caused by $E$. coli 075 .

\section{Discussion}

A mixed growth from a mid-stream specimen of urine is generally considered to have been derived from contamination during collection. The appearance of several distinct colony types in moderate numbers from a specimen might prompt the reporting of 'a mixed growth of doubtful significance'. It is suggested that care be exercised in the reporting of mixed growths and that the findings can be checked by culture of more specimens.
I am grateful to Dr B. Rowe, of the Salmonella and Shigella Reference Laboratory, Colindale for typing the organisms, and to Mrs J. Turner for secretarial help.

\section{References}

Dootson, P. H., MacLaren, D. M., and Titcombe, D. H. M. ڤ) (1973). The distribution of urinary O-groups of Escherichia coli in urinary infections and in the normal faecal flora. Proceedings 2nd National Symposium, ed. W. Brumfitt and A. A. Asscher, Urinary Tract Infection, pp. 139-145. Oxford University Press, London.

Grüneberg, R. N., Leigh, D. A., and Brumfitt, W. (1968). Escherichia coli serotypes in urinary tract infection. Urinary Tract Infection, Proceedings 1st National Symposium, eds. F. O'Grady and W. Brumfitt, pp. 68-79. Oxford University Press, London.

Mabeck, C. E., Ørskov, F., and Ørskov, I. (1971). Escherichia coli serotypes and renal involvement in urainary-tract $O$ infection. Lancet, 1, 1312-1314.

O'Grady, F. W., Richards, B., McSherry, M. A., O'Farrell, S. M., and Cattell, W. R. (1970). Introital enterobacteria, urinary infection, and the urethral syndrome. Lancet, 2, 1208-1210.

Spencer, A. G., and Mulcahy, D., Shooter, R. A., O'Grady, $\bar{\partial}$ F. W., Bettleheim, K. A., and Taylor, J. (1968). Escherichia coli serotypes in urinary-tract infection in a medical ward. Lancet, 2, 839-842. 